\title{
Evaluation of the push-out bond strength of ProRoot MTA and Biodentine after removal of calcium hydroxide and triple antibiotic paste
}

\section{Fatih Tulumbacı ${ }^{1} \mathbb{D}$, Merve Erkmen Almaz ${ }^{\mathbb{D}}$, Volkan Arıkan² ${ }^{\mathbb{D}}$, Merve Safa Mutluay3}

${ }^{1}$ Yıldırım Beyazıt University, Faculty of Dentistry, Department of Pediatric Dentistry, Ankara, Turkey

${ }^{2}$ Kırıkkale University, Faculty of Dentistry, Department of Pediatric Dentistry, Kırıkkale, Turkey

${ }^{3}$ Kırıkkale University, Health Services College, Kırıkkale, Turkey

\section{Correspondence:}

\section{Dr. Merve ERKMEN ALMAZ}

Kırıkkale University, Faculty of

Dentistry, Department of Pediatric

Dentistry, Kırıkkale, Turkey.

E-mail:dt.merveerkmen@gmail.com

Received: 11 May 2018

Accepted: 11 July 2018

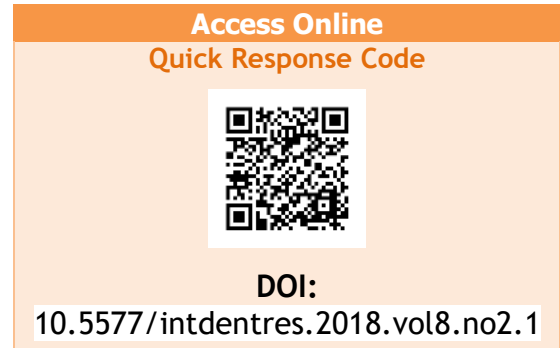
of Calcium Hydroxide and Triple Antibiotic Paste. Int Dent Res 2018;8(2):50-5.
Aim: To evaluate the effect of calcium hydroxide $(\mathrm{CH})$ and triple antibiotic paste (TAP) on the push-out bond strength of ProRoot ${ }^{\circledR}$ MTA and Biodentine ${ }^{\circledR}$.

Methodology: Root canals of 120 human teeth were instrumented using rotary files. To obtain a standard diameter of $1.5 \mathrm{~mm}$, the roots were instrumented with a \#6 Peeso reamer. The reamers passed $1 \mathrm{~mm}$ beyond the apex point to simulate open apices. The roots were randomly assigned into the following groups: Group 1 was administered calcium hydroxide ( $\mathrm{CH})$; Group 2 was administered triple antibiotic paste (TAP); and Group 3 was a control group and had no medicament. The medicaments were removed after 3 weeks. Thereafter, the specimens were divided into two subgroups $(n=20)$ according to which calcium silicate-based cement, ProRoot MTA (Dentsply Maillefer, Ballaigues, Switzerland) or Biodentine (Septodont, France), was applied. The push-out test was performed, and the data were analyzed statistically using one-way ANOVA and by Tukey's post hoc test.

Results: In both the ProRoot MTA and Biodentine groups, pairwise comparisons between medicaments showed similar values to the control group $(p>0.05)$. Overall, there was a predominance of cohesive failures between root dentin and the cements.

Conclusions: ProRoot MTA and Biodentine showed similar bond strength values, and prior application of TAP or $\mathrm{CH}$ did not affect the bond strength significantly.

Keywords: Biodentine, calcium hydroxide, mineral trioxide aggregate, ProRoot MTA, triple antibiotic paste 


\section{Introduction}

Dental trauma or irreversible pulp inflammation to young teeth may result in pulp necrosis and incomplete root formation. The challenges of root canal treatment for immature teeth are cleaning, shaping and obturation because of open apices (1). In addition, root fractures may occur in these teeth due to thin and/or weakened root walls (2). A new technique called regenerative endodontic treatment (RET) involves tissue engineering in the root canal system of immature teeth (3). For successful results of RET, inflamed pulp tissue is completely removed and bacteria is eliminated from the root canal space; elimination is provided by effective applications with various irrigation solutions and medicaments $(4,5)$.

Antibiotic pastes and calcium hydroxide $(\mathrm{CH})$ are frequently used medicaments for RET $(6,7)$. Triple antibiotic paste (TAP) is the most commonly used root canal disinfectant during RET since its introduction by Hoshino et al. in 1996. TAP consists of ciprofloxacin, metronidazole and minocycline and has effective antimicrobial properties (8). Also, $\mathrm{CH}$ is prevalently used as an endodontic intracanal dressing material because of its high $\mathrm{pH}$ and appropriate antibacterial effects (9). It has been successfully used to disinfect the canal during $\operatorname{RET}(7,10)$.

After the RET period, mineral trioxide aggregate (MTA), which is a calcium silicate-based material, was generally placed on the coronal 3-4 mm section of the root canal. MTA has biocompatible, conductive and inductive properties which allows it to chemically bond to the root dentin wall $(11,12)$. Nevertheless, MTA remains subject to some concerns: it has a long setting time, is difficult to manipulate, has a low resistance to compression and flow capacity, causes discoloration of tooth structure and has a high cost $(11,13)$.

Alternative calcium silicate-based materials were introduced to replace MTA $(14,15)$. Biodentine $(B D)$, one of these materials, is a tooth-coloured, bioactive cement used for apexification, repair of root perforations and retrograde root filling as an MTA (16).

In the literature, there is a limited number of studies evaluating push-out bond strength of BD using intracanal medicaments for the RET procedure (17). Therefore, the aim of this study was to evaluate the effect of intracanal medicaments ( $\mathrm{CH}$ and TAP) used during RET on the push-out bond strength of an MTA and $\mathrm{BD}$ to root canal dentin.

\section{Materials and Methods}

One hundred twenty single-rooted human mandibular premolar teeth, which were freshly extracted for periodontal or orthodontic reasons, were selected and stored in $0.1 \%$ thymol until the commencement of the experiment. The teeth were examined under an operating microscope (Euromex, Arnhem, Germany) and excluded if there were any root caries, cracks or fractures. Preoperative radiographs were taken to validate a single canal without canal treatment, internal resorption or calcification. The specimens were decoronated using a diamond disk with water cooling to standardize root length to $15 \mathrm{~mm}$.

The root canals were prepared using ProTaper rotary instruments (Dentsply Maillefer, Ballaigues, Switzerland) up to size F5. To achieve a standard internal diameter of $1.5 \mathrm{~mm}$ and to simulate immature teeth, reamers (Dentsply Maillefer, Ballaigues, Switzerland) between \#1 and \#6 were used in the root canals and passed $1 \mathrm{~mm}$ beyond the apex to simulate open apices. The canals were irrigated by using $2 \mathrm{ml}$ of sodium hypochlorite $(\mathrm{NaOCl})$ during instrumentation. After instrumentation, the canals were irrigated with 5 $\mathrm{ml}$ of $\mathrm{NaOCl}$ and $5 \mathrm{ml}$ of $17 \%$ ethylenediaminetetraacetic acid (EDTA) solution. Finally, the root canals were flushed with $5 \mathrm{ml}$ of distilled water and dried using paper points.

The roots were randomly assigned into three groups. Group 1 was treated with calcium hydroxide $(\mathrm{CH})$; Group 2 was given triple antibiotic paste (TAP); and Group 3 acted as a control and had no medicament.

Preparation of Intracanal Medicaments

Group 1: Calcium hydroxide powder (Kalsin; Spot Diș Deposu A.S, Izmir, Turkey) mixed with distilled water.

Group 2: A mixture of metronidazole (Flagyl $₫ 500$ $\mathrm{mg}$ tablet, AventisPharma S.A., France), ciprofloxacin (Cipro ${ }^{\circledR} 500 \mathrm{mg}$ tablet, Biofarma ilaç San. ve Tic. A.S.., Turkey) and minocycline (Minoz ${ }^{\mathrm{TM}} 50 \mathrm{mg}$ tablet, Ranbaxy Lab. Ltd., India).

Group 3: No medicament.

The coronal access of the root canals was sealed with a cotton pellet and temporary filling material (Cavit; 3M ESPE, Seefeld, Germany). The specimens were stored at $37{ }^{\circ} \mathrm{C}$ in $100 \%$ humidity for 3 weeks.

Afterward, intracanal medicaments were removed by rinsing with $10 \mathrm{ml}$ of $\mathrm{NaOCL}$ followed by $5 \mathrm{ml}$ of distilled water. The specimens were divided into two subgroups $(n=20)$ according to the calcium silicatebased cement (ProRoot MTA or BD) applied. The subgroups were as follows:

$$
\mathrm{CH}+\text { MTA Group }
$$$$
\text { TAP + MTA Group }
$$ 
Control + MTA Group

$\mathrm{CH}+$ Biodentine Group

TAP + Biodentine Group

Control + Biodentine Group

ProRoot MTA (Dentsply Maillefer, Ballaigues, Switzerland) and BD (Septodont, Saint-Maur, France) were mixed according to the manufacturer's instructions. The test materials were placed into the canals with the aid of a lentulo spiral (Dentsply, Konstantz, Germany). By using pluggers (Dentsply, Konstantz, Germany), the materials were condensed vertically.

Approximately $3 \mathrm{~mm}$ of MTA or BD were placed in the coronal third of the canals and gently applied to the dentinal walls with a moistened cotton pellet. The cavities were filled with a temporary filling material. Finally, the specimens were stored at $37{ }^{\circ} \mathrm{C}$ in $100 \%$ humidity for one week.

Then, the specimens were cut horizontally from the coronal root region using a low-speed precision diamond saw (Micracut 201, Metkon, Bursa, Turkey) under water cooling to produce slices approximately 1 $\mathrm{mm}$ thick. The thickness of each slice was measured with a digital calliper (Teknikel, Istanbul, Turkey) with an accuracy of $0.001 \mathrm{~mm}$. The push-out test was performed in a universal testing machine (Lloyd Instruments Ltd, Fareham, UK) at a crosshead speed of $1 \mathrm{~mm} / \mathrm{min}$ by using cylindrical plungers (Figure 1 ). The diameter of each plunger was approximately $90 \%$ of the slice's diameter.

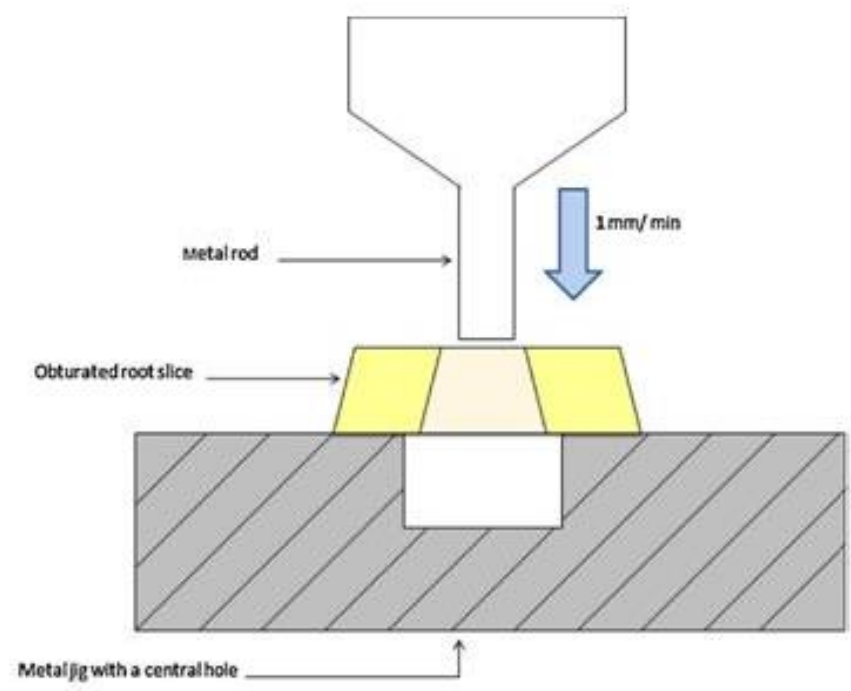

Figure 1. Schematic drawing of the push-out test.
The maximum load applied to the filling material before failure was recorded in newtons $(\mathrm{N})$ and converted to megapascals ( $\mathrm{MPa}$ ) according to the following formula:

Push-out bond strength $(\mathrm{MPa})=$ Maximum load $(\mathrm{N})$ / Adhesion area of root filling $(\mathrm{A})\left(\mathrm{mm}^{2}\right)$.

The adhesion surface area of the root canal filling (A) was calculated by the following:

$$
\left(\pi r^{1}+\pi r^{2}\right) \times L \text {, }
$$

where $\pi=3.14 ; r^{1}$ and $r^{2}=$ smaller and larger radii, respectively; $\mathrm{L}=\sqrt{\left(r^{1}-r^{2}\right)^{2}+h^{2}}$. The $\mathrm{h}$ equals the thickness of the slice in $\mathrm{mm}(18)$.

After the test procedure, each specimen was examined under an operating microscope (Euromex, Arnhem, Germany) at 30x magnification to determine the mode of fracture. Three types of failure were categorized: adhesive, between the filling materials and root dentin; cohesive, within the filling materials or root dentin; and mixed, a combination of cohesive and adhesive failures (19).

\section{Statistical Analysis}

The data were analysed using one-way ANOVA, and Tukey's post hoc test was performed for multiple comparisons. The significance level was set at $p<0.05$. All data were processed using SPSS 16.0 statistical software (SPSS Inc., Chicago, IL, USA).

\section{Results}

The mean and standard deviation of the push-out bond strength values are shown in Table 1. The statistical analysis indicated that bond strength values of both silicate cements were not significantly affected by the intracanal medicaments $(P>0.05)$. For $B D$ and MTA materials, the highest push-out bond strength values were obtained with TAP groups (TAP + MTA and TAP + Biodentine). The bond strength of TAP + Biodentine was significantly higher than $\mathrm{CH}+$ Biodentine, $\mathrm{CH}+\mathrm{MTA}$ and the control + MTA groups $(p<0.05)$.

The modes of failure are listed in Table 2 . Cohesive failures were observed most frequently in all groups. 
Table 1. Push-out bond strength values (MPa, mean, standard deviation) of calcium silicate cements with respect to intracanal medicaments

\begin{tabular}{cc} 
Groups & Bond strength \\
\hline Control +MTA Group & $8.31 \pm 2.01$ \\
CH + MTA Group & $8.14 \pm 2.44$ \\
TAP + MTA Group & $8.98 \pm 1.87$ \\
\hline Control + Biodentine Group & $8.65 \pm 2.99$ \\
\hline CH + Biodentine Group & $7.70 \pm 2.40$ \\
\hline TAP + Biodentine Group & $10.11 \pm 2.25$ \\
\hline
\end{tabular}

Table 2. Failure modes for each group

\begin{tabular}{cccc|}
\hline Groups & Failure Modes & Mixed \\
\hline Control +MTA Group & 1 & Cohesive & 7 \\
\hline CH + MTA Group & 2 & 12 & 4 \\
\hline TAP + MTA Group & 1 & 14 & 4 \\
\hline Control + Biodentine Group & 1 & 15 & 4 \\
\hline CH + Biodentine Group & 2 & 15 & 2 \\
\hline TAP + Biodentine Group & 1 & 16 & 2 \\
\hline
\end{tabular}

\section{Discussion}

After RET, calcium silicate-based materials were used to form bacteria-tight seals in the pulp space (11). MTA has been widely used for RET $(11,20)$. Nevertheless, MTA has some disadvantages; therefore, BD could be an alternative material used with RET (14, 15). The push-out test has been shown to be a reliable method for evaluating the displacement resistance of the filling material during operative procedures and mastication (21-23). Furthermore, pulp scaffolding may be affected by the force applied to the coronal barrier during the placement of restorative material (20).

MTA is a type of hydraulic cement which sets in the presence of fluid. When MTA comes into contact with a fluid, it continues to dissolve and hydroxyapatite-like crystals form between the MTA and dentinal walls $(12,16,24)$. In the present study, the specimens were stored for 1 week in a moist environment to simulate clinical conditions.

BD has similar properties to MTA (except for zirconium oxide and calcium chloride, a setting accelerator water reducing agent). In both materials, a calcium silicate hydrate colloidal gel layer and apatite deposits form on the surface; these interact with tissue fluids and enhance the sealing ability and bond strength of the materials (25). The setting time of $B D$ is relatively short (12 $\mathrm{min}$ ) and has favourable handling characteristics; its placement is less time-consuming than MTA. Thus, coronal restoration can be performed at the same appointment $(26,27)$.

In the present study, both $\mathrm{CH}+\mathrm{MTA}$ and $\mathrm{CH}+\mathrm{BD}$ groups displayed lower mean bond strength values than other groups. This could be explained by CH's reaction with dentin and may cause the disruption of dentin collagen. The high alkalinity of $\mathrm{CH}$ deteriorates the bond between hydroxyapatite and collagenous fibrils and reduces the dislocation resistance of MTA and BD to root dentin $(28,29)$. On the contrary, the push-out bond strength of MTA and BD was not affected by $\mathrm{CH}$ in the study of Nagas et al. and Centenaro et al. (17, 30).

The present study has shown that BD displayed higher push-out bond strength values compared to MTA, except for the $\mathrm{CH}+\mathrm{BD}$ group. Nagas et al. have evaluated the dislocation resistance of BD and MTA to the root dentin after applying various intracanal medicaments ( $\mathrm{CH}$, TAP, Augmentin, Ledermix); BD yielded higher bond strength values than MTA. This result was explained as BD having a potential to enhance penetration into the medicament-free dentinal tubules because of its smaller particle size, leading to improved bond strength (17). Also, the study 
of Guneser et al. showed that BD established significantly stronger bonds to root dentin than MTA after being exposed to various endodontic irrigants (31). Similarly, Centenaro et al. stated that BD yielded higher push-out bond strength values compared with those of MTA, regardless of the use of $\mathrm{CH}$ (30). On the contrary, the study of Alsubait et al., which evaluated push-out bond strength of ProRoot MTA and BD without medicaments, showed that bond strength of $B D$ is like MTA (14). This may be due to the absence of any medicaments or irrigants.

The results of the present study showed that intracanal medicaments $(\mathrm{CH}$ and TAP) did not significantly affect the dislocation resistance of MTA and BD to root dentin. This result is similar to the study of Topcuoglu et al. They stated that $\mathrm{CH}$ and TAP did not influence the dislocation resistance of MTA to root dentin (20). Conversely, in the study of Nagas et al. compared with the control groups, TAP decreased the debonding force of MTA and BD (17). The difference in the removal procedures may have led to the differing results. In the present study we did not use EDTA for removal of medicaments.

In the present study, highest bond strength values were observed in TAP groups. In accordance with these results, the study of Akçay et al. found that the TAP group displayed higher bond strength values than $\mathrm{CH}$ and a double antibiotic paste (DAP) group (18). This may be due to the binding of residual minocycline to calcium ions via chelation, which could increase bond strength after application of TAP (32). On the other hand, in the study of Oktay et al. the push-out bond strength of the $\mathrm{CH}$ group was found significantly higher than the TAP group of a calcium-phosphate-silicatebased cement (EndoSequence root repair material) (33). Also, Felippe et al. and Bidar et al. found that $\mathrm{CH}$ had a positive effect on the bond strength of calcium silicate-based sealers $(34,35)$. Nagas et al. stated that the reaction of calcium silicate-based cements with residual calcium hydroxide resulted in improvement of the marginal adaptation (17).

\section{Conclusions}

Within the limitations of this study, BD and ProRoot MTA showed similar bond strength values, and it can be concluded that prior application of TAP and $\mathrm{CH}$ had no significant negative effect on the bond strength of the materials.

When previous literatures were evaluated, there was found a need for new studies regarding the influence of antibiotic medicaments and $\mathrm{CH}$ on the bond strength of calcium silicate-based cements.
Peer-review: Externally peer-reviewed.

Author Contributions: Conception - F.T.; Design - M.E.A.; Supervision M.E.A., F.T.; Materials - V.A.; Data Collection and/or Processing - M.E.A.; Analysis and/or Interpretation-F.T., M.E.A.; Literature Review-M.S.M.; Writer -F.T., M.E.A.; Critical Review - V.A., M.S.M.

Conflict of Interest: Noconflict of interest was declared by the authors.

Financial Disclosure: The authors declared that this study has received no financial support.

\section{References}

1. Trope M. Treatment of the immature tooth with a non-vital pulp and apical periodontitis. Dent Clin North Am. 2010;54(2):313-24. (Crossref)

2. Wilkinson KL, Beeson TJ, Kirkpatrick TC. Fracture resistance of simulated immature teeth filled with resilon, gutta-percha, or composite. J Endod 2007;33(4):480-3 (Crossref)

3. Nakashima M, Huang GTJ. Pulp and dentin regeneration. Stem cells in craniofacial development and regeneration. New Jersey:John Wiley and Sons, p:461-84, 2013. (Crossref)

4. Athanassiadis B, Abbott PV, Walsh LJ. The use of calcium hydroxide, antibiotics and biocides as antimicrobial medicaments in endodontics. Aust Dent J 2007;52(1 (Suppl)):S64-S82. (Crossref)

5. Estrela C, Holland R, Bernabé PFE, Souza Vd, Estrela CRA. Antimicrobial potential of medicaments used in healing process in dogs' teeth with apical periodontitis. Braz Dent J. 2004;15(3):181-5. (Crossref)

6. Bose $R$, Nummikoski $P$, Hargreaves K. A retrospective evaluation of radiographic outcomes in immature teeth with necrotic root canal systems treated with regenerative endodontic procedures. J Endod 2009;35(10):1343-9. (Crossref)

7. Cehreli ZC, Isbitiren B, Sara S, Erbas G. Regenerative endodontic treatment (revascularization) of immature necrotic molars medicated with calcium hydroxide: a case series. J Endod 2011;37(9):1327-30. (Crossref)

8. Hoshino E, Kurihara-Ando N, Sato I, Uematsu H, Sato M, Kota $\mathrm{K}$, et al. In-vitro antibacterial susceptibility of bacteria taken from infected root dentine to a mixture of ciprofloxacin, metronidazole and minocycline. Int Endod J 1996;29(2):125-30. (Crossref)

9. Zmener O, Pameijer $\mathrm{CH}$, Banegas $\mathrm{G}$. An in vitro study of the $\mathrm{pH}$ of three calcium hydroxide dressing materials. Dent Traumatol 2007;23(1):21-5. (Crossref)

10. Chueh LH, Ho YC, Kuo TC, Lai WH, Chen YH, Chiang CP. Regenerative endodontic treatment for necrotic immature permanent teeth. J Endod 2009;35(2):160-4. (Crossref)

11. Parirokh $M$, Torabinejad $M$. Mineral trioxide aggregate: a comprehensive literature review--Part III: Clinical applications, drawbacks, and mechanism of action. J Endod 2010;36(3):40013. (Crossref)

12. Sarkar NK, Caicedo R, Ritwik P, Moiseyeva R, Kawashima I. Physicochemical basis of the biologic properties of mineral trioxide aggregate. J Endod 2005;31(2):97-100. (Crossref)

13. Chang SW. Chemical characteristics of mineral trioxide aggregate and its hydration reaction. Restor Dent Endod 2012;37(4):188-93. (Crossref)

14. Alsubait SA, Hashem Q, AlHargan N, AlMohimeed K, Alkahtani A. Comparative evaluation of push-out bond strength of 
ProRoot MTA, bioaggregate and biodentine. J Contemp Dent Pract. 2014;15(3):336-40. (Crossref)

15. Nayak G, Hasan MF. Biodentine-a novel dentinal substitute for single visit apexification. Restor Dent Endod 2014;39(2):120-5. (Crossref)

16. Khetarpal A, Chaudhary S, Talwar S, Ravi R, Verma M. Revascularization of immature permanent tooth with periapical lesion using a new biomaterial-A case report. Int J Dent Sci Res 2013;1(1):20-2. (Crossref)

17. Nagas E, Cehreli ZC, Uyanik MO, Vallittu PK, Lassila LVJ. Effect of several intracanal medicaments on the push-out bond strength of ProRoot MTA and Biodentine. Int Endod J 2016;49(2):184-8. (Crossref)

18. Akcay M, Arslan H, Topcuoglu H. S, Tuncay O. Effect of calcium hydroxide and double and triple antibiotic pastes on the bond strength of epoxy resin-based sealer to root canal dentin. J Endod. 2014;40(10):1663-7. (Crossref)

19. Prado M, Simao RA, Gomes BP. Effect of different irrigation protocol on resin sealer bond strength to dentin. J Endod. 2013;39(5):689-92. (Crossref)

20. Topçuoğlu HS, Arslan H, Akçay M, Saygili G, Çakici F, Topçuoğlu $G$. The effect of medicaments used in endodontic regeneration technique on the dislocation resistance of mineral trioxide aggregate to root canal dentin. J Endod 2014;40(12):2041-4. (Crossref)

21. Tagger M, Tagger E, Tjan AH, Bakland LK. Measurement of adhesion of endodontic sealers to dentin. J Endod 2002;28(5):351-4. (Crossref)

22. Huffman BP, Mai S, Pinna L, Weller RN, Primus CM, Gutmann $\mathrm{JL}$, et al. Dislocation resistance of ProRoot Endo Sealer, a calcium silicate-based root canal sealer, from radicular dentine. Int Endod J 2009;42(1):34-46. (Crossref)

23. da Cunha LF, Furuse AY, Mondelli RF, Mondelli J. Compromised bond strength after root dentin deproteinization reversed with ascorbic acid. J Endod 2010;36(1):130-4. (Crossref)

24. Hashem AA, Wanees Amin SA. The effect of acidity on dislodgment resistance of mineral trioxide aggregate and bioaggregate in furcation perforations: an in vitro comparative study. J Endod 2012;38(2):245-9. (Crossref)

25. Butt N, Talwar S, Chaudhry S, Nawal RR, Yadav S, Bali A. Comparison of physical and mechanical properties of mineral trioxide aggregate and Biodentine. Indian J Dent Res. 2014;25(6):692-7. (Crossref)

26. Khetarpal A, Chaudhary S, Talwar S, Verma M. Endodontic management of open apex using Biodentine as a novel apical matrix. Indian J Dent Res. 2014;25(4):513-6. (Crossref)

27. Bani M, Sungurtekin-Ekçi E, Odabaş ME. Efficacy of Biodentine as an Apical Plug in Nonvital Permanent Teeth with Open Apices: An In Vitro Study. BioMed Research International, vol. 2015, Article ID 359275, 4 pages, 2015. (Crossref)

28. Yassen GH, Vail MM, Chu TG, Platt JA. The effect of medicaments used in endodontic regeneration on root fracture and microhardness of radicular dentine. Int Endod J 2013;46(7):688-95. (Crossref)

29. Sahebi S, Moazami F, Abbott P. The effects of short-term calcium hydroxide application on the strength of dentine. Dent Traumatol 2010;26(1):43-6. (Crossref)

30. Centenaro CF, Santini MF, da Rosa RA, Nascimento AL, Kuga MC, Pereira JR, Só MV. Effect of calcium hydroxide on the bond strength of two bioactive cements and SEM evaluation of failure patterns. Scanning. 2016;38(3):240-4. (Crossref)

31. Guneser MB, Akbulut MB, Eldeniz AU. Effect of various endodontic irrigants on the push-out bond strength of biodentine and conventional root perforation repair materials. J Endod 2013;39, 380-4. (Crossref)

32. Tanase S, Tsuchiya H, Yao J, Ohmoto S, Takagi N, Yoshida S. Reversed-phase ion-pair chromatographic analysis of tetracycline antibiotics. Application to discolored teeth. J Chromatogr B Biomed Sci Appl. 1998 Mar 20;706(2):279-85. (Crossref)

33. Oktay EA, Ersahan S, Gokyay S. Effect of intracanal medicaments used in endodontic regeneration on the push-out bond strength of a calcium-phosphate-silicate-based cement to dentin. Pak J Med Sci. 2018;34(2):310-315. (Crossref)

34. Felippe WT, Felippe MC, Rocha MJ. The effect of mineral trioxide aggregate on the apexification and periapical healing of teeth with incomplete root formation. Int Endod J 2006;39, 2-9. (Crossref)

35. Bidar M, Disfani R, Gharagozloo S, Khoynezhad Rouhani A. Medication with calcium hydroxide improved marginal adaptation of mineral trioxide aggregate apical barrier. J Endod 2010;36, 1679-82. (Crossref) 